\title{
ICONOS CLAVES DEL FORMATIVO EN TARAPACÁ (CHILE): EL ARTE RUPESTRE DE TAMENTICA Y SU DISTRIBUCIÓN REGIONAL
}

\author{
KEY ICONS OF FORMATIVE IN TARAPACÁ (CHILE): TAMENTICA'S ROCK \\ ART AND ITS REGIONAL DISTRIBUTION
}

\author{
Gloria Cabello ${ }^{1,2}$ y Francisco Gallardo ${ }^{3,4}$
}

\begin{abstract}
Este artículo presenta una nueva mirada al emblemático sitio de Tamentica (quebrada de Guatacondo, norte de Chile). Se describen y sistematizan tres motivos rupestres que, por su redundancia y variabilidad, consideramos iconos claves del período Formativo tarapaqueño, a saber: el Ser Antropomorfo con Tocado Dentado, el Ave con Alas Extendidas y la Balsa de Cuero de Lobo Tripulada. Asimismo, revisamos su distribución en otros soportes de Tarapacá y Antofagasta. Finalmente se discute el rol que pudieron tener estos iconos en el contexto social de los grupos humanos en momentos en que nuevos procesos de intensificación económica, creciente sedentarismo y nucleamiento poblacional, exigen nuevas formas de interacción entre los habitantes de oasis, quebradas, costa y altiplano.
\end{abstract}

Palabras claves: iconos claves, período Formativo, arte rupestre, Tamentica, Tarapacá.

This article provides a new look at the emblematic site of Tamentica (Guatacondo Canyon, northern Chile). We describe and systematize three rock art motifs which, because of their redundancy and variability, we consider key icons of the Formative Period in Tarapacá, namely: the Anthropomorphic Being with Dentate Headdress, the Bird with Extended Wings, and the Manned Sea Lion Hide Raft. We also review the distribution of these icons on other materials from Tarapaca to Antofagasta. Finally, we discuss the potential role of these icons in their social context, as human groups were undergoing new processes of economic intensification, increasing sedentary life, and population nucleation, which required from the inhabitants of the oases, canyons, coast and highlands to find new ways of interaction between them.

Key words: Key icons, Formative Period, rock art, Tamentica, Tarapacá.

Pocos sitios de arte rupestre son tan emblemáticos del norte de Chile como Tamentica en la quebrada de Guatacondo (Figura 1). Registrado en los años sesenta en asociación a las investigaciones realizadas en el complejo habitacional temprano G-1 y vinculado al período Formativo (1.500 a.C.-800 d.C.) por asociación iconográfica a un figurilla de oro recuperada en un cementerio contemporáneo a la aldea, fue parcialmente publicado mediante fotografías y dibujos (Mostny 1970a; Mostny y Niemeyer 1983; Tolosa 1963, 1967). Sin embargo, poco sabemos de su variabilidad formal y menos aún del repertorio de imágenes correspondiente a esta época.

Tamentica es un sitio dominado por el grabado y si se compara con el arte rupestre parietal disperso en la quebrada es, con poca duda, el lugar que concentra el mayor número de imágenes. Su importancia en el pasado debió ser de larga data, pues su iconografía muestra motivos de todas las épocas prehispánicas ${ }^{1}$. Asunto cuyo valor histórico es mayor si se consideran los sustanciales cambios de diseño de un mismo motivo que, por su número, redundancia y distribución tanto en el sitio como en áreas vecinas, consideraremos como iconos claves. Un icono clave es básicamente una imagen cuya recurrencia en el tiempo y el espacio sugiere un compromiso de significado social que promueve un tipo de consenso con efectos directos en la cohesión social, que no necesariamente debe ser reducida a la etnicidad, sino más bien a distintos niveles de integración entre grupos e individuos

\footnotetext{
Centro de Investigaciones del Hombre en el Desierto, Av. General Velásquez 1775, Arica, Chile. glcabello@gmail.com Av. Holanda 1745 dpto. 304, Providencia. Santiago, Chile.

Museo Chileno de Arte Precolombino, Bandera 361, Santiago, Chile.

4 Centro Interdisciplinario de Estudios Interculturales e Indígenas, Pontificia Universidad Católica de Chile, Campus San Joaquín, Avda. Vicuña Mackenna 4860, Macul, Santiago, Chile. fgallardo.ibanez@ gmail.com
} 


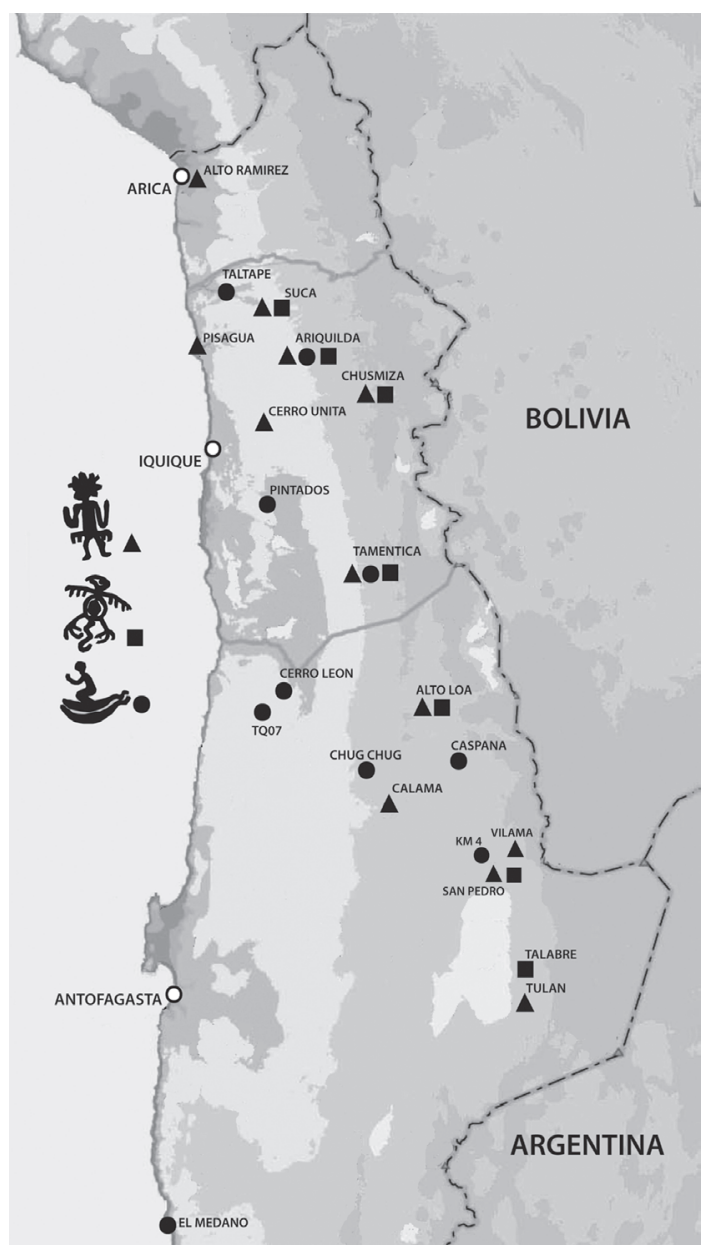

Figura 1. Distribución de los iconos en el área de estudio. Distribution of the icons in the study area.

cuyos vínculos deben ser estrechados (Gamble 1982; Mege 2003; Wobst 1977). Más aún, podemos sugerir que la interacción social que implicaba el movimiento de personas, bienes y conocimientos requería la construcción de un ambiente de intereses mutuos, cuya eficacia simbólica y social debió anidarse en rituales de reciprocidad como los descritos en la época colonial (p.ej., Martínez 1995). Estos vínculos de carácter político entre distintos agentes participantes en la movilidad e intercambio pudieron ser expresados, conservados y materializados en el arte rupestre, en especial si consideramos que la distribución regional de este imaginario visual apelaba a un mismo sistema iconográfico, cuyos orígenes sostenemos aparecen durante el período Formativo.

\section{Iconos Formativos y su Presencia en Tamentica}

Mientras el arte rupestre formativo de la región de Antofagasta ha sido claramente establecido desde el punto de vista estilístico y contextual (p.ej., Berenguer 2004; Gallardo et al. 2012), los estudios visuales para este período en la Región de Tarapacá permanecen aún en un nivel de menor integración histórica y cultural. Aunque por ahora no existen registros rupestres de escala regional que permitan definiciones estilísticas para el formativo tarapaqueño, trataremos aquí un conjunto de iconos de distribución regional y larga persistencia temporal que también comprometen localidades del desierto de Atacama.

Tamentica es uno de los sitios rupestres conocidos con mayores referencias en la literatura arqueológica, aunque nunca estudiado de manera sistemática en relación con el imaginario formativo y su incidencia en la fundación de la historia visual tarapaqueña.

En Tamentica los grabados se concentran sobre una puntilla rocosa en la ladera norte de la quebrada de Guatacondo. Afloramiento de granodiorita que, según Briones y Ajata (2004), actuaría como muro de contención de las aguas subterráneas, haciéndolas surgir, creando un oasis con abundante agua, flora y fauna (Figura 2). Destaca la asociación del sitio a distintos senderos que permiten la comunicación no sólo con los asentamientos a lo largo de la quebrada, sino también con otras localidades, p.ej., Mani-Quillagua al sur, Pica al norte, CollahuasiAlto Loa al oriente y Salar de Llamara-Guanillos al poniente (Cabello et al. 2013; Gallardo et al. 2012). Hecho que, sumado a la representación de personajes de distintos ambientes geográficos y en actividades económicas diversas, han concedido a Tamentica un lugar destacado en el tráfico interregional prehispánico (Meighan 1980; Mostny 1970a, 1970b; Mostny y Niemeyer 1963; Núñez 1985; Tolosa 1967).

Del conjunto rupestre de este sitio sólo tres motivos cumplen a cabalidad la regla de redundancia y variabilidad que distingue a los iconos claves y cuyos orígenes formativos pueden ser determinados por asociación a artefactos de cronología conocida (Gallardo 1996): (1) El "Personaje de los dos cetros" o "Personaje frontal" que aquí llamaremos "Ser Antropomorfo con Tocado Dentado"; (2) La figura del "Hombre cóndor" o "cóndor" que designaremos 
"Ave con alas extendidas"; (3) La "Balsa de cuero de lobo tripulada".

A propósito de nuestra investigación, fueron relevados 445 motivos presentes en 26 de los 80 bloques de Tamentica, los cuales exhiben la mayor cantidad de representaciones y en los que se reconoció la iconografía en estudioº ${ }^{2}$ Estos diseños comprometen el $14,6 \%(\mathrm{~N}=65)$ de la muestra, resultando interesante que se ubican preferentemente en el sector más accesible del sitio (NE), donde se encuentran más motivos por panel y mayor presencia de superposición ${ }^{3}$. Es más, destaca el hecho que dos tercios de los casos en estudio se concentran en tres de estos bloques, dos de los cuales presentan los tres iconos claves (bloques 25 y 32), mientras el tercero (bloque 7) exhibe el Ave con Alas Extendidas y la Balsa de Cuero de Lobo Tripulada (Tabla 1).

A causa de la particular relevancia de esta imaginería en la prehistoria de Tarapacá y Antofagasta, proponemos entregar a continuación una sistematización de estos iconos en el sitio de Tamentica, considerando sus antecedentes, su distribución y contexto social durante el período Formativo en estas regiones, así como también su persistencia en épocas posteriores.

\section{El Ser Antropomorfo con Tocado Dentado}

El "Personaje de los dos cetros" o "Personaje frontal" que aquí llamaremos "Ser Antropomorfo con Tocado Dentado" es sin duda la imagen mejor conocida del sitio (p.ej., Berenguer 1981; Chacama y Espinosa 1997; Focacci y Erices 1972-1973; Mostny y Niemeyer 1983). Característica del norte de Chile durante el período Formativo, en especial de la región de Tarapacá, esta imagen aparece en tejidos, cestos, adornos metálicos y arte rupestre. Es una figura humana representada frontalmente, de pie con los brazos flectados hacia arriba y con un tocado dentado que cubre casi todo el contorno de su cabeza. Entre otros elementos menos regulares se observan también adornos en pecho y codos, faldellines y artefactos elongados en sus manos.

En Tamentica esta figura corresponde al 2,25\% $(\mathrm{N}=10)$ de la muestra en estudio. Representada siempre de frente, exhibe variedad de atributos. Sólo siete poseen tocado dentado, de ellos cinco tienen los brazos en $\mathrm{W}^{4}$, incluyendo cuatro que conforman una composición simétrica al replicarse en traslación sobre un eje horizontal. Solamente una presenta faldellín desdoblado, las demás parecieran portar algún tipo de vestimenta como falda continua

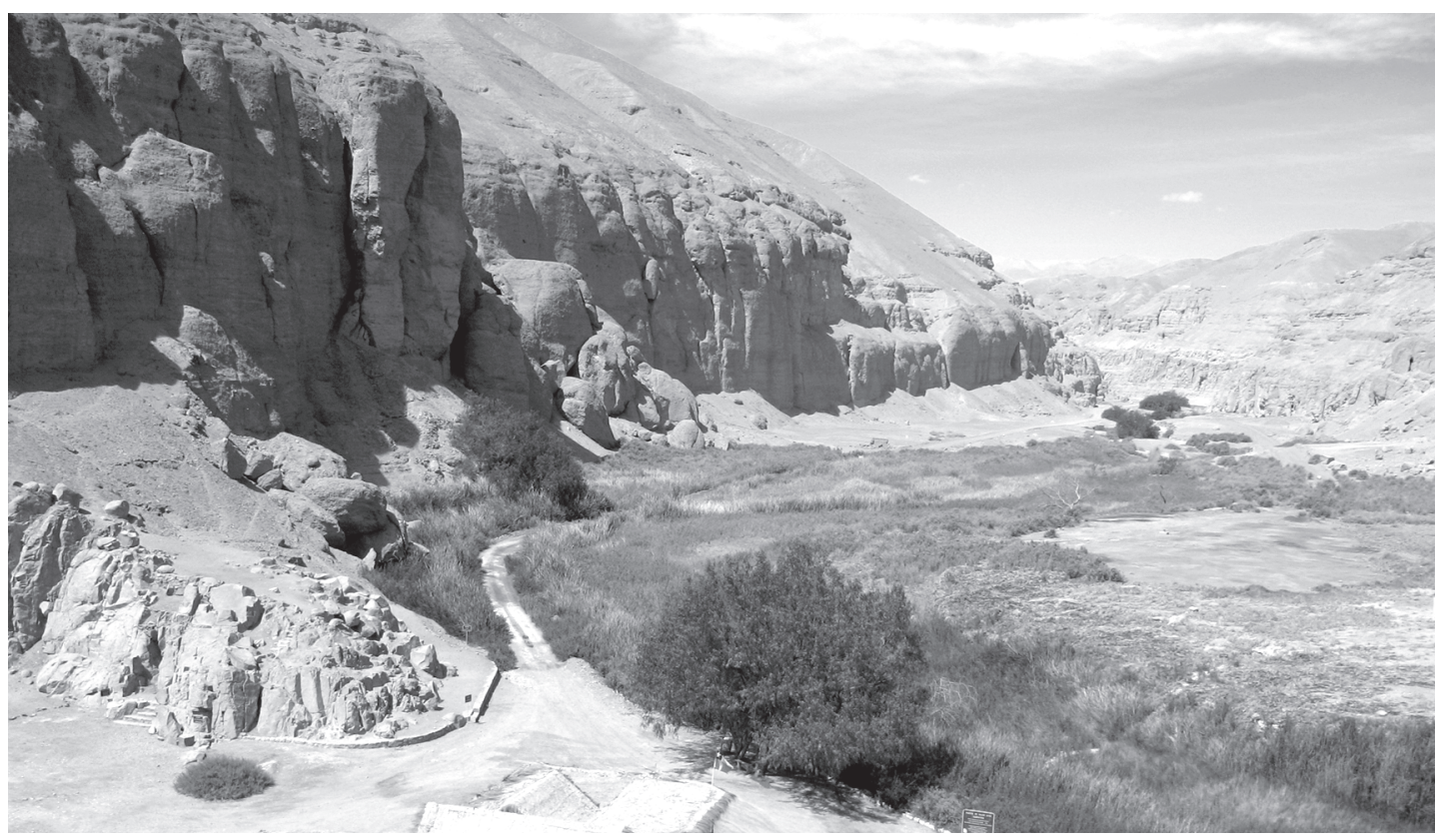

Figura 2. Vista general de la quebrada de Guatacondo y el sitio arqueológico de Tamentica (abajo a la izquierda).

Overview of Guatacondo Canyon and the archaeological site of Tamentica (bottom left). 
Tabla 1. Distribución de los iconos claves en el sitio de Tamentica. Distribution of key icons Tamentica site.

\begin{tabular}{|c|c|c|c|c|c|}
\hline Bloque $\mathrm{N}^{\mathrm{o}}$ & $\begin{array}{c}\text { Motivos } \\
\text { por bloque }\end{array}$ & & & & $\begin{array}{c}\text { Otros } \\
\text { motivos }\end{array}$ \\
\hline 1 & 1 & & & 1 & \\
\hline 2 & 4 & & & & 4 \\
\hline 7 & 58 & & 6 & 4 & 48 \\
\hline 11 & 6 & & & & 6 \\
\hline 12 & 4 & & & & 4 \\
\hline 13 & 1 & & & & 1 \\
\hline 16 & 10 & & 2 & & 8 \\
\hline 18 & 3 & & & 2 & 1 \\
\hline 20 & 9 & & & & 9 \\
\hline 21 & 9 & & 1 & & 8 \\
\hline 22 & 8 & & 2 & 1 & 5 \\
\hline 25 & 90 & 4 & 7 & 1 & 78 \\
\hline 26 & 51 & & 4 & & 47 \\
\hline 31 & 1 & 1 & & & \\
\hline 32 & 97 & 5 & 11 & 5 & 76 \\
\hline 36 & 19 & & 1 & & 18 \\
\hline 37 & 12 & & 1 & & 11 \\
\hline 38 & 7 & & & & 7 \\
\hline 40 & 14 & & & & 14 \\
\hline 41 & 5 & & 1 & & 4 \\
\hline 46 & 15 & & 4 & & 11 \\
\hline 49 & 12 & & & 1 & 11 \\
\hline 71 & 2 & & & & 2 \\
\hline 73 & 1 & & & & 1 \\
\hline 74 & 3 & & & & 3 \\
\hline 77 & 3 & & & & 3 \\
\hline Totales & 445 & 10 & 40 & 15 & 380 \\
\hline
\end{tabular}

o túnica, siguiendo la nomenclatura propuesta por Montt (2002) (Figura 3A). Otro ejemplar que posee faldellín desdoblado y brazos en $\mathrm{W}$ pero no tocado, exhibe un elemento en la cintura que es también visible en las figuras antropomorfas de una pintura estilo Cueva Blanca y del geoglifo de Cerro Unita (Montt 2002). Este antropomorfo está además rodeado por cuatro puntos que siguen la simetría axial de la imagen central (Figura 3B). Existe también una representación un poco menor que no presenta extremidades superiores pero sí tocado dentado y una vestimenta con puntos y líneas cuyo extremo inferior es semejante a la cabeza.

De ellos difiere una representación de gran tamaño que, no obstante su tocado dentado, posee un brazo hacia abajo y porta objetos en sus manos, uno de los cuales es alargado con una protuberancia en uno de sus extremos (Figura 3C). Este objeto puede identificarse con los dardos arrojadizos con pesas estabilizadoras que han sido hallados en contextos arqueológicos fechados en el 500 a.C. y que son también visibles en pinturas estilo Confluencia del Formativo Temprano (1.500-500 a.C.) (Focacci y Erices 1972-1973; Montt 2004; Núñez, Cartajena, Carrasco, de Souza et al. 2006).

Por último, se halla una figura con un tocado diferente (dos apéndices rectos al centro y dos laterales que caen hacia abajo), cuyos brazos se oponen a las piernas, sugiriendo un individuo sentado (Figura 3D). Representación que incluimos en este conjunto por su valor cronológico, debido a que aparece junto al Ser Antropomorfo con Tocado Dentado en una bolsa anillada del cementerio Formativo Pisagua D (p.ej., Montt 2002).

Otras representaciones de este personaje en la región tarapaqueña son la figura de oro recuperada de un cementerio cercano (G-5A), los grabados de Suca, Ariquilda 1 y Chusmisa y el geoglifo de 
Cerro Unita (Chacama y Espinosa 1997; Meighan 1980; Montt 2002; Sepúlveda et al. 2005; Vilches y Cabello 2011). En la región de Antofagasta aparece en un textil de Chorrillos, en un grabado del Salar de Atacama (Vilama Sur) y en una pintura del Alto Loa de estilo Cueva Blanca (2Loa 231), cuya extensión temporal abarca desde el Formativo Medio (500 a.C.-100 d.C.) al Tardío (100-800 d.C.) (Gallardo 2009a; Sinclaire 1997). Tampoco podemos dejar de mencionar sus vínculos con la iconografía textil Alto Ramírez formativo tardía del valle de Azapa (Focacci y Erices 1972-1973; Cases y Montt 2013). Si a estas sumamos el par de placas de oro ofrendadas a un neonato de la aldea de Tulan y la decoración de un cesto de Topater, resulta que las representaciones más antiguas serían previas al 500 a.C. (Núñez, Cartajena, Carrasco y de Souza 2006; Llagostera 2004) (Figura 4A) $)^{5}$. Hecho que no invalida las asociaciones de este icono con la litoescultura Tiwanaku y su influencia en las tabletas de rapé de San Pedro de Atacama (Berenguer 1981; Chacama y Espinosa 1997; Llagostera y Costa 1984; Núñez 1985), particularmente si se tienen en cuenta los fechados más recientes que retrotraen la emergencia de dicha cultura al primer milenio a.C. (Augustyniak 2004). A su vez, es posible que el icono se mantuviera vigente hasta el Intermedio Tardío (1.000-1.400 d.C.) en Tarapacá (Vilches y Cabello 2010, 2011).

Por último, quisiéramos señalar que a diferencia de lo que originalmente propusieran Chacama y Espinosa (1997) como requisitos mínimos del personaje (posición frontal erecta, brazos en $\mathrm{V}$ y el rostro irradiado, más la posible presencia de objetos en las manos), coincidimos con una idea posterior que propone que los recursos visuales estables se
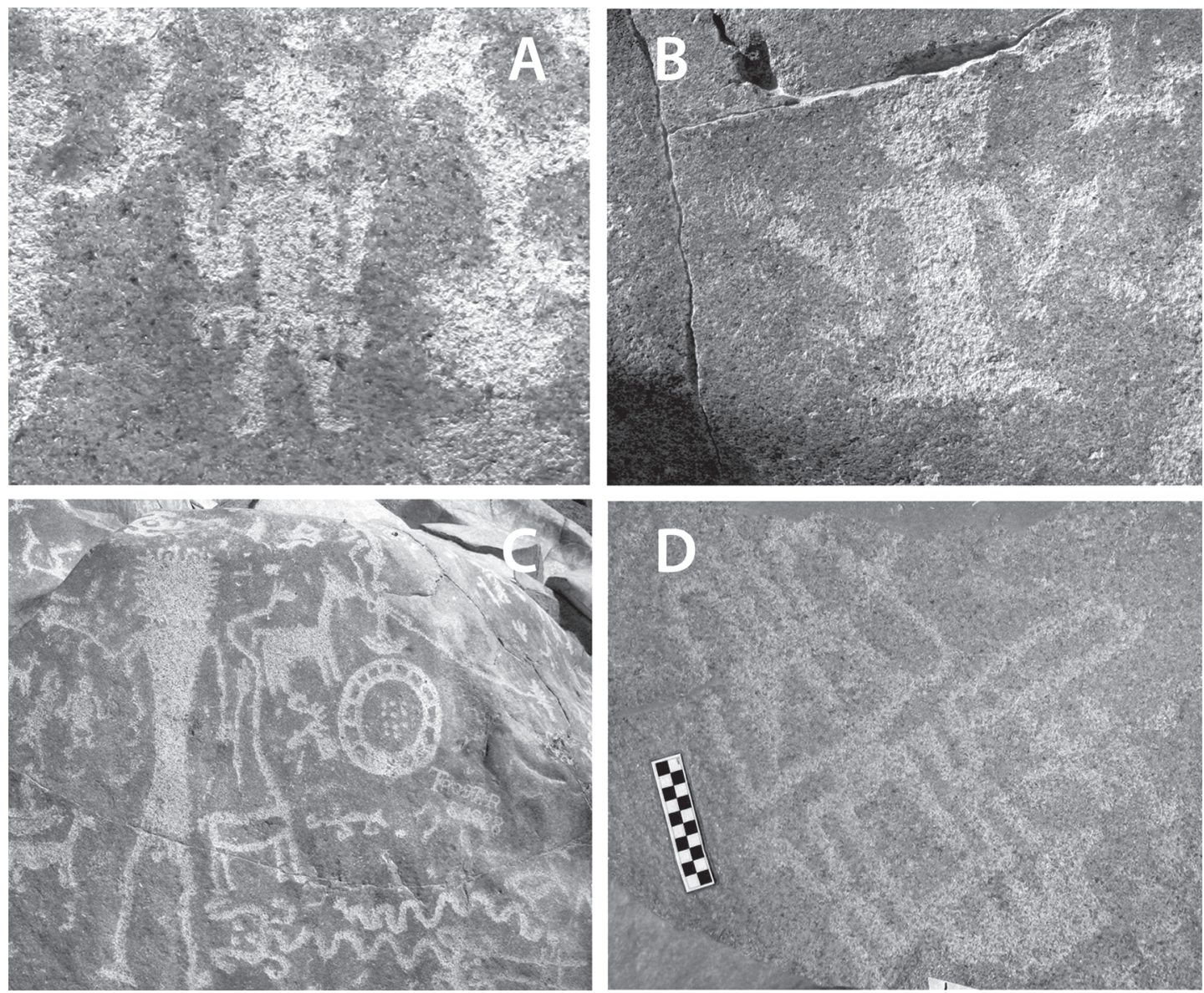

Figura 3. Ser Antropomorfo con Tocado Dentado en Tamentica: (A) $11 \mathrm{~cm}$ de alto; (B) $14 \mathrm{~cm}$ de alto; (C) $80 \mathrm{~cm}$ de alto; (D) 33 $\mathrm{cm}$ de alto.

Anthropomorphic Being with Dentate Headdress at Tamentica: (A) $11 \mathrm{~cm} \mathrm{height;} \mathrm{(B)} 14 \mathrm{~cm}$ height; (C) $80 \mathrm{~cm} \mathrm{height;} \mathrm{(D)} 33 \mathrm{~cm} \mathrm{height.}$ 
remiten más bien a la representación antropomorfa en frontalidad con sus brazos alzados, construida bajo "un esquema de axialidad en el cual la figura está gobernada por la ortogonalidad y la simetría" (Montt 2002:17). Y que a pesar de la variabilidad en la combinación de los demás elementos, permite reconocer al icono en cualquier tipo de soporte en el que se represente.

\section{El Ave con Alas Extendidas}

La figura del "Hombre cóndor" o "cóndor" que designaremos "Ave con alas extendidas" tiene también una amplia distribución en el norte de Chile (Chacama y Espinosa 1997; Mostny y Niemeyer 1963, 1983). En lo general es un ave de cuerpo macizo y largas alas mostradas de frente, con su cabeza y pico de gran tamaño construidos de perfil (Chacama y Espinosa 1997) (Figuras 4B y 5). En su cuerpo y alas hay indicaciones de la presencia de plumaje y sus patas exhiben tres largos dedos cuyo aspecto crea el efecto de poderosas garras.

En Tamentica este motivo corresponde al 9\% $(\mathrm{N}=40)$ de las imágenes de nuestra muestra. Exhibe gran diversidad en su representación, pero con tendencias que nos permiten agruparlas en cuatro conjuntos. Primero, tenemos siete ejemplares que muestran cabeza redondeada y pico generalmente recto; cuerpos de diversas formas; alas que suelen estar en posición horizontal, rectas o curvas cortas, con o sin los apéndices que se interpretan como plumaje; existiendo pocos casos con patas (Figura 5A). Segundo, 18 casos en que el pico y la cabeza fueron ejecutados a partir de una sola línea curva, a veces con un punto en el centro a modo de ojo; el cuerpo es en general oval y en ocasiones circunscribe una figura circular, alternando sectores de cuerpo lleno; alas principalmente curvas y largas extendidas hacia abajo con apéndices por el interior; patas rectas que terminan en tres dedos, las cuales se han interpretado como garras; a veces entre estas extremidades se disponen dos líneas rectas cortas o bien una larga línea ondulada a modo de cola (Mostny y Niemeyer 1983) (Figura 5B). Tercero, seis casos en que se perciben atributos humanos: cuerpo cuadrangular que se asemeja a una túnica y piernas rectas a veces con pies también rectos, no obstante conserven generalmente las alas y el pico curvo (Figura 5C). Cuarto, nueve ejemplares en que se representa sólo una parte del ave, sea la

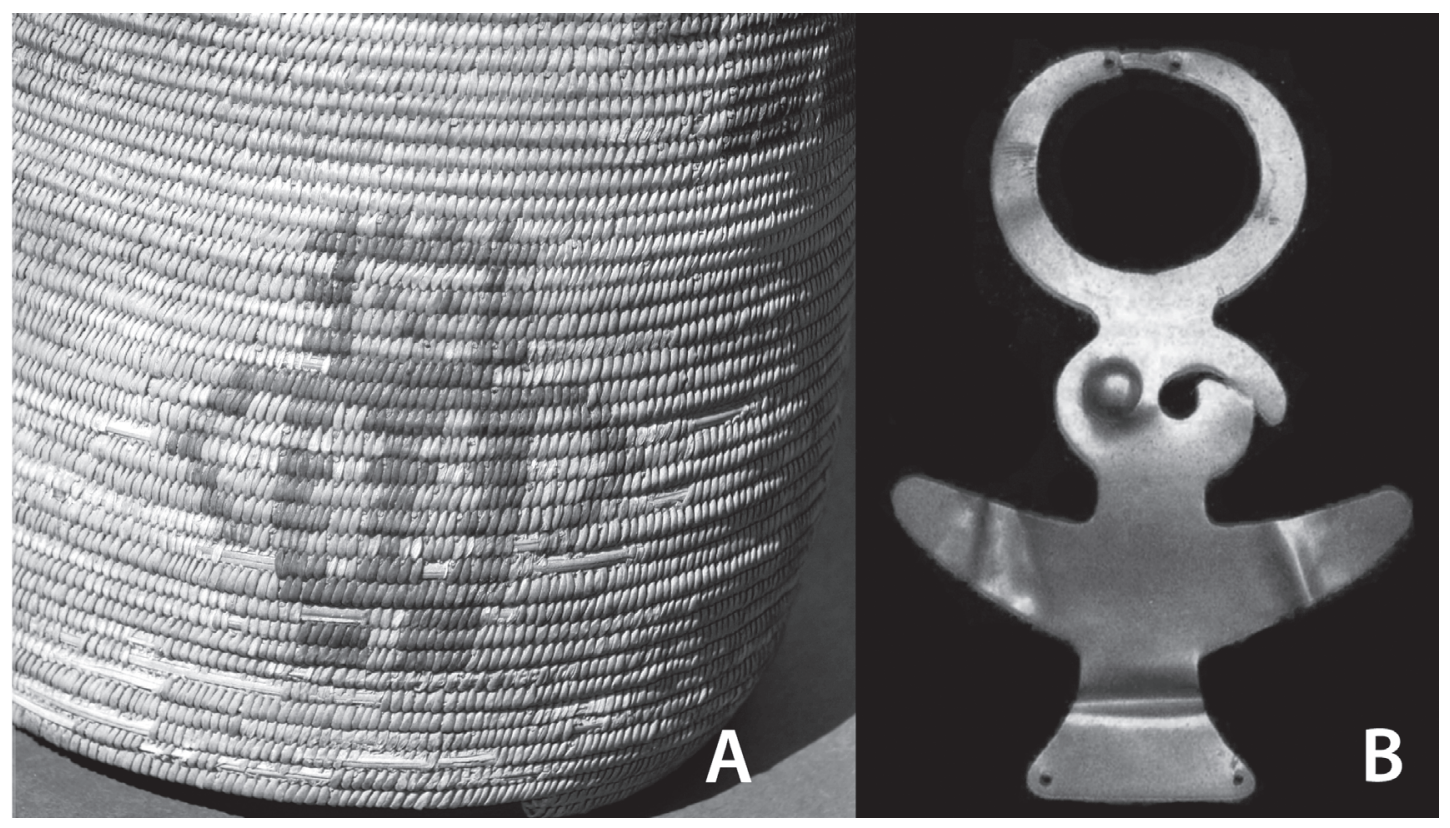

Figura 4. (A) Ser Antropomorfo con Tocado Dentado en un cesto de Topater (fotografía gentileza del proyecto FONDECYT 1110702). (B) Psittacidae en adorno nasal de oro, Noroeste Argentino (González 1977:Figura 256).

(A) Anthropomorphic Being with Dentate Headdress on a basket from Topater site (Photo courtesy of FONDECYT 1110702). (B) Psittacidae on a golden nose ring, Argentine Northwest (González 1977:Figure 256). 

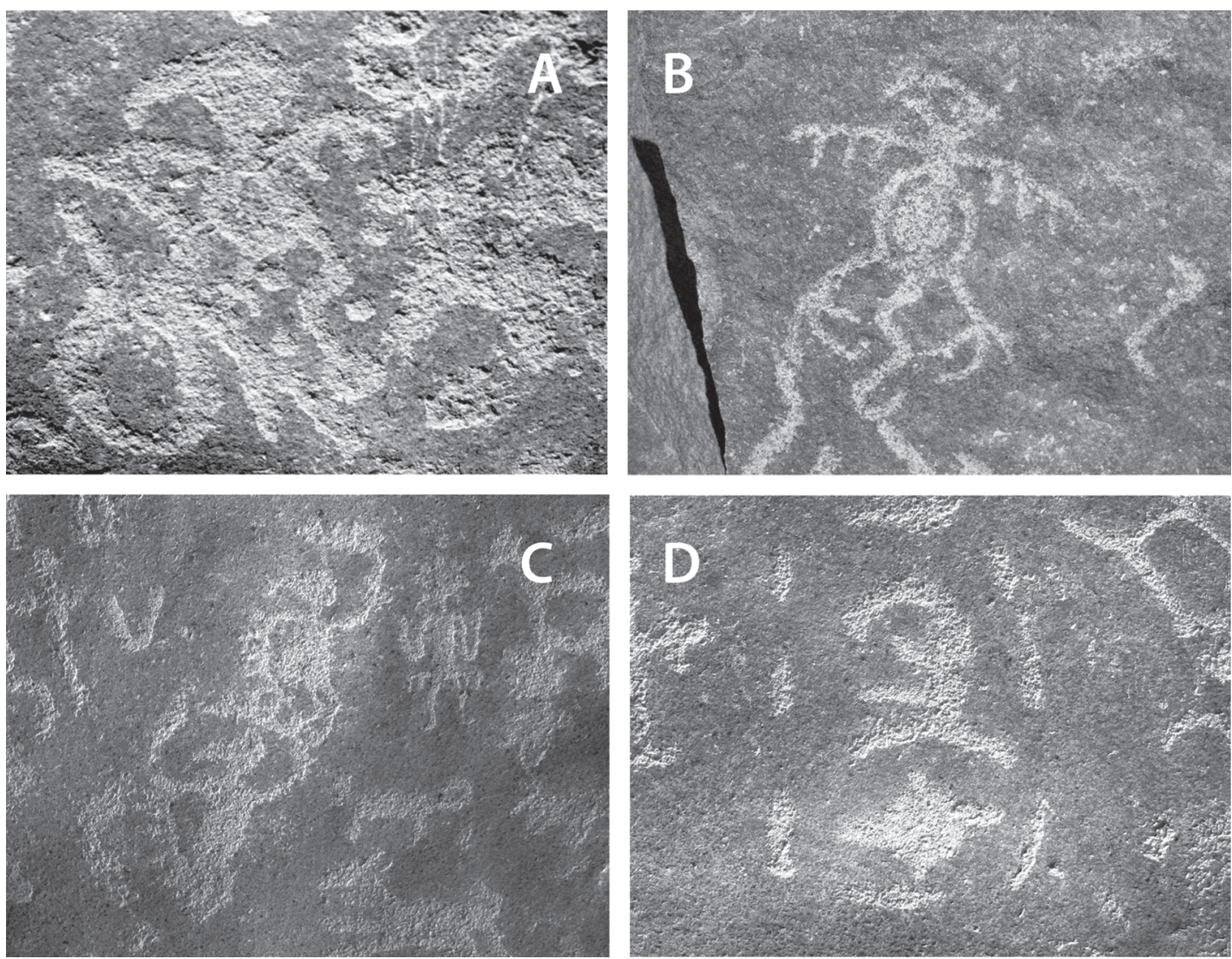

Figura 5. Ave con Alas Extendidas en Tamentica: (A) 13,5 cm de alto; (B) $18 \mathrm{~cm}$ de alto; (C) alto total $25 \mathrm{~cm}$; (D) $21 \mathrm{~cm}$ de alto total. Bird with Extended Wings at Tamentica: (A) $13.5 \mathrm{~cm}$ height; (B) $18 \mathrm{~cm}$ height; (C) total height $25 \mathrm{~cm}$; (D) total height $21 \mathrm{~cm}$.

pata con tres dedos o cabeza y pico según la solución gráfica del segundo grupo (una sola línea curva) (Figura 5D). En este caso presentarían además alas o cuerpo, el que puede ser una larga línea ondulada o en zigzag y extremidades superiores que pudieran bien ser alas o brazos.

Resulta interesante que el bloque que concentra la mayor cantidad de los motivos en estudio (vid. supra) posee una representación del cuarto conjunto cuya cabeza fue ejecutada ligeramente sobre una de las patas de un ave del segundo grupo, que a su vez sobrepone un ala a uno de los antropomorfos “jorobados" en composición escénica (sensu Mostny y Niemeyer 1983). Secuencia en la ejecución de motivos que nos permite sustentar que el grupo cuatro constituye una simplificación del segundo, con el que comparten la solución visual de cabezapico y la pata de tres dedos. Pues una vez que la codificación del icono ha sido incorporada por el receptor, ya no resulta necesaria la reproducción de todos sus atributos, sólo bastan algunos para reconocer la forma original (p.ej., Donnan 1978; Gombrich 1969; Wobst 1977).

Más complejos resultan el primer y tercer grupo, cuya variabilidad en la forma de cuerpo y pico, la presencia/ausencia de otros atributos (patas o plumaje en las alas), así como la desarrollada expresión de movimiento de algunos, nos sugieren podrían ir al final de la secuencia, pero se hace necesario corroborarlo con nuevos casos de análisis.

Independiente de lo anterior, consideramos que la forma del segundo conjunto constituye el icono definitivo que se estandariza en Tarapacá y se distribuye hacia los Valles Occidentales y Atacama, posiblemente previo al Intermedio Tardío. Esto se sustenta en la presencia del Ave con Alas Extendidas en un panel grabado de estilo Taira Tulan de Talabre y en pinturas del Alto Loa donde se le superpone el Ser Antropomorfo con Tocado Dentado (Berenguer 2004; Gallardo 2009a; Gallardo et al. 2012). Todas 


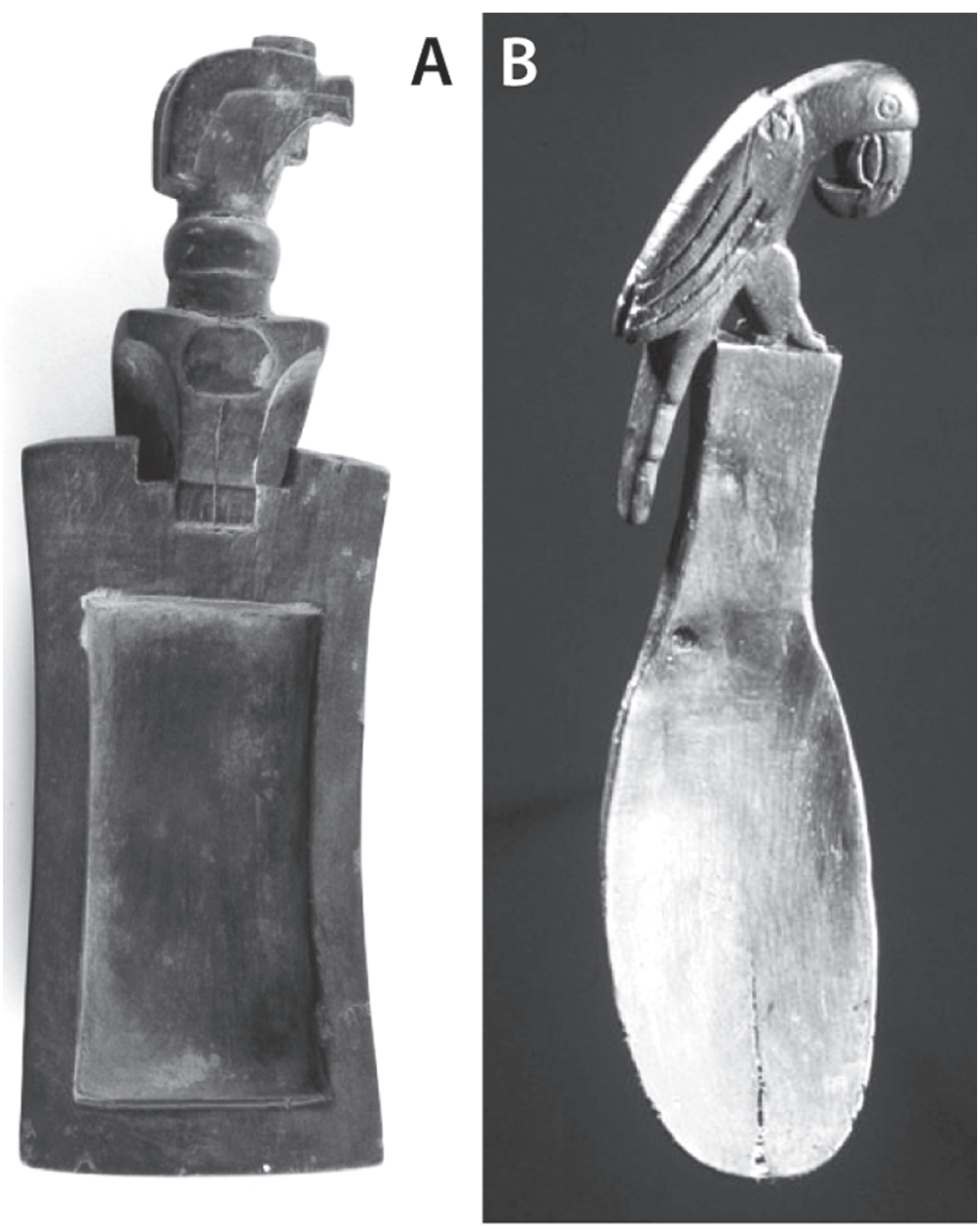

Figura 6. (A) Vultur en tableta para consumo de alucinógenos, madera, sitio Coyo Oriente (fotografía gentileza de Constantino Manuel Torres). (B) Psittacidae en cuchara, madera, sitio Coyo Oriente (fotografía gentileza del Museo Chileno de Arte Precolombino).

(A) Hallucinogenic Snuff Tray with Vultur, wood, Coyo Oriente site (photo courtesy of Constantino Manuel Torres). (B) Spoon with a Psittacidae, wood, Coyo Oriente site (photograph courtesy of Museo Chileno de Arte Precolombino).

ellas son representaciones que nos remiten al período Formativo Temprano, momento en el cual estarían circulando como artefactos visuales por rutas establecidas entre Guatacondo y el Alto Loa vía Miño-Collahuasi (Aschero 1988; Gallardo et al. 2012).

Vale la pena mencionar que, independiente de sus variaciones, consideramos que todas estas figuras remiten a la representación de una misma especie. En efecto, la mayoría de los autores le llaman cóndor (p.ej., Chacama y Espinosa 1997; Mostny y Niemeyer 1963, 1983; Sepúlveda et al. 2005). Interpretación que es avalada por Chacama (2004) al sostener que la forma del pico y de las alas y las patas terminadas en garras permiten identificarla al menos con el género Vultur. Atributos que a nuestro juicio podrían corresponder a más de un tipo de ave. Más aún, el motivo en estudio no presenta las características de un cóndor: grandes crestas sobre el pico y la frente, pico grueso ganchudo y un collar de plumas en la base del cuello. Propiedades que son recurso común de su representación en otros soportes, como las tabletas para consumo de alucinógenos y las escudillas de madera del período Medio en San Pedro de Atacama (Coyo Oriente, Catarpe y Séquitor) (Llagostera y Costa 1984) (Figura 6A). Por el contrario, la curvatura de la cabeza y pico, el ojo destacado y la cola larga se ciñen más bien a 
la anatomía de un Psittacidae, ave tropical que ha sido representada en cucharas y pilones de madera en el mismo sitio Coyo Oriente (Llagostera 2004) (Figura 6B). Es más, podría tratarse del guacamayo azul y amarillo (Ara ararauna), cuyas plumas son constantemente ofrendadas en tumbas del norte de Chile, encontrándose incluso un ejemplar en el cementerio intermedio tardío de Pica-8, momento en el que también se representa en la iconografía textil de Valles Occidentales (Catalán 2006).

Representaciones más tempranas de esta ave se registran en una escultura lítica ofrendada al mencionado infante de Tulan, en dos pequeñas figurillas de oro recuperadas del cementerio formativo Chiu-Chiu 273 y en un adorno nasal en lámina de oro de un sitio del período Temprano del noroeste argentino que presenta similar solución gráfica para cabeza-pico y ojo que los del segundo conjunto de Tamentica (González 1977; Núñez, Cartajena, Carrasco, de Souza et al. 2006; Thomas et al. 2002) (Figura 4B).
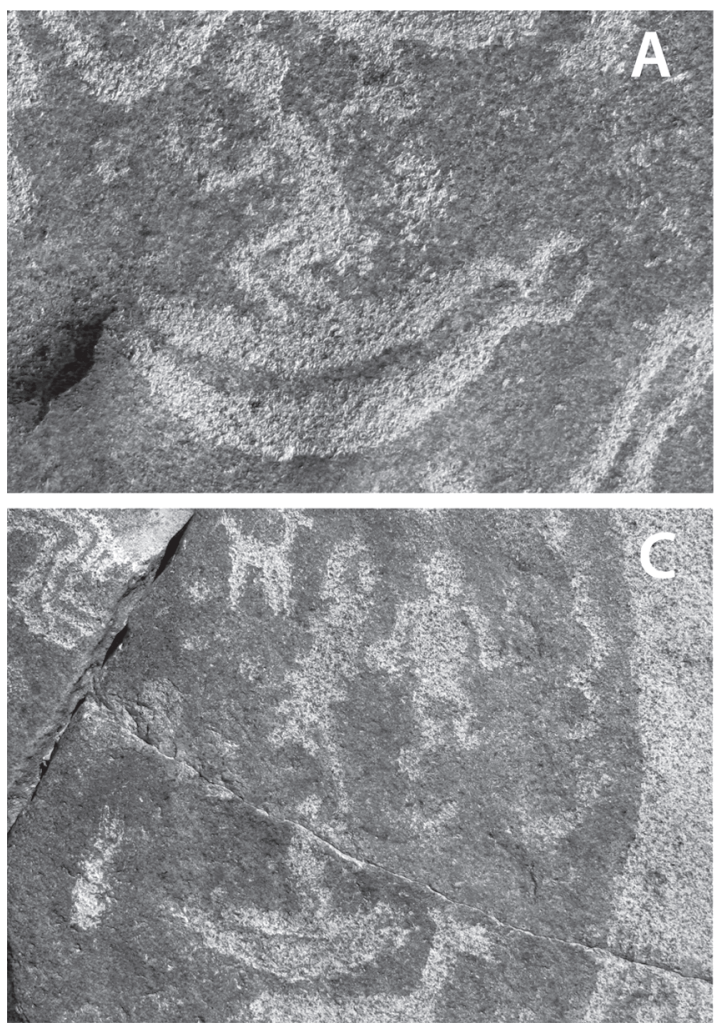

\section{La Balsa de Cuero de Lobo Tripulada}

La "Balsa de cuero de lobo tripulada" es característica del arte rupestre tarapaqueño y de El Médano en Taltal, aunque en este último caso las figuras humanas presentan escasos atributos vinculables a cabeza, cuerpo y extremidades (Niemeyer 2010). La representación más básica incluye dos flotadores curvados hacia arriba mirados a "vuelo de pájaro" con un tripulante "sentado" o de pie con las piernas semiflectadas. Resulta frecuente la presencia de artefactos y acciones relativas al tripulante, pudiendo variar entre pesca con sedal, caza con arpón o uso de remo.

En Tamentica esta figura corresponde al 3,3\% $(\mathrm{N}=15)$ de la muestra en estudio. Todas las representaciones exhiben un solo tripulante, el que suele estar de pie con las piernas semiflectadas (ocho casos) o rectas (tres ejemplares), aunque existen tres casos en que se muestra desde el torso hacia arriba, dando la idea de que van sentados (Figura 7A
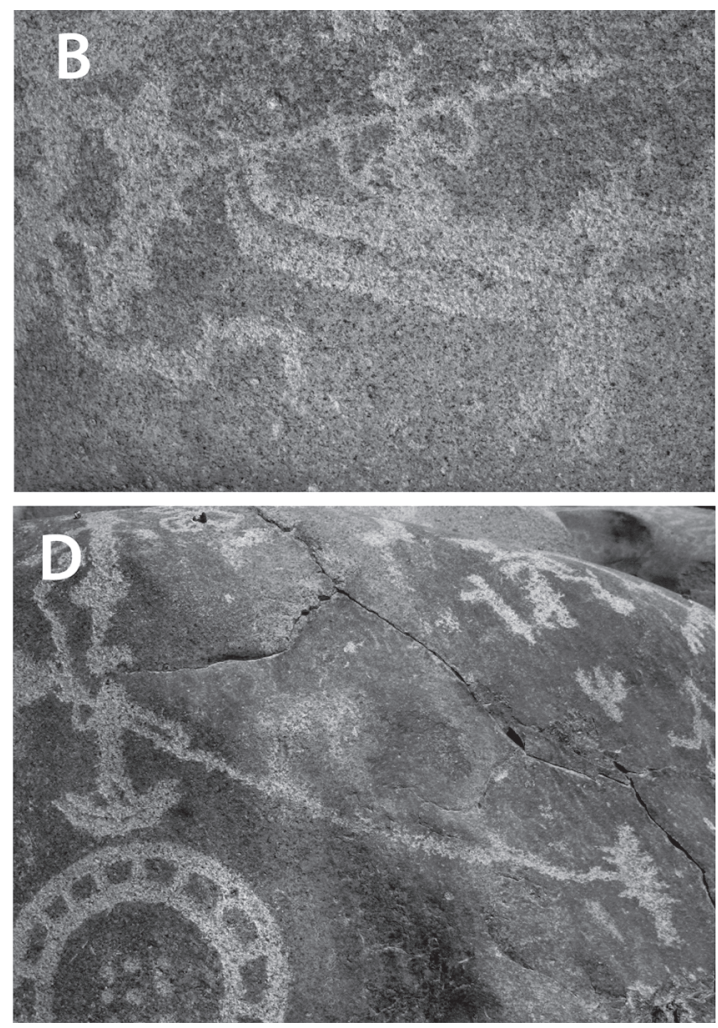

Figura 7. Balsa de Cuero de Lobo Tripulada en Tamentica: (A) $15 \mathrm{~cm}$ de alto; (B) $31 \mathrm{~cm}$ de alto; (C) $12 \mathrm{~cm}$ de alto; (D) altura balsa tripulada $24 \mathrm{~cm}$.

Manned Sea Lion Hide Raft at Tamentica: (A) $15 \mathrm{~cm}$ height; (B) $31 \mathrm{~cm}$ height; (C) $12 \mathrm{~cm}$ height; (D) Manned boat height $24 \mathrm{~cm}$. 
y B). Independiente de lo anterior, el navegante se representa en forma equitativa de semiperfil o de frente (8 y 7 casos, respectivamente). En similar proporción, los brazos se encuentran hacia arriba o al frente, nueve veces vinculados a una línea recta y dos a una curva que interpretamos como arpón/remo y sedal. Elementos que muestran diversa longitud y terminación, incluyendo la sujeción de presas que, por morfología y tamaño, interpretamos como peces (Figura 7C y D). La cabeza de los tripulantes suele ser del tipo circular, con algunos casos que exhiben uno o dos apéndices hacia arriba o hacia un lado, semejantes a los de una representación del estilo Confluencia del Formativo Temprano atacameño. En ella, el tripulante aparece sentado, portando un tocado con dos apéndices en $\mathrm{V}$ hacia la derecha del espectador y arponeando una presa (Gallardo et al. 1999) (Figura 8A). Igual que en esta pintura, las embarcaciones de Tamentica son siempre de dos cuerpos en forma de media luna (salvo un caso), diez de las cuales registran también las terminaciones en espiral u onduladas. Esta forma de representación hace un innegable llamado a los dos flotadores de la balsa de cuero de lobos registrada en la región desde el período Colonial temprano (Ballester y Gallardo 2011; Mostny y Niemeyer 1963).

Como señalamos antes, la representación precolombina de embarcaciones tripuladas se restringe a las regiones de Tarapacá y Antofagasta, particularmente en grabados y geoglifos cuyas características técnicas de ejecución y contextos iconográficos lo sitúan hacia el período Intermedio Tardío. Se observa en los geoglifos de Pintados en la Pampa del Tamarugal, Los Balseros y Cerro León en las cercanías de Quillagua, TQ07 sobre la ruta que une este poblado con la costa y Chug-Chug en Calama (Blanco 2012; Briones y Castellón 2005; Núñez 1976; Pimentel 2011); así como en el grabado del kilómetro 4 de la ruta que une San Pedro de Atacama y Río Grande (Le Paige 1977; Lindeberg 1969). En todos ellos, los tripulantes comparten varios de los elementos mencionados para Tamentica: brazos arriba y arpón o piernas semiflectadas y postura de semiperfil para destacar movimiento o animación (Pimentel 2011), no obstante que la balsa sea siempre de un solo cuerpo.

En Taltape, valle de Camarones, existe un grabado que muestra una posible balsa de un cuerpo con extremos levantados y un tripulante de perfil con piernas semiflectadas y un objeto en las manos
(Niemeyer 1969; Mostny y Niemeyer 1983). Por la forma de la cabeza pudiera corresponder a un animal (cánido o félido) o bien poseer un tocado en V. Tipo de adorno cefálico que es característico en las pinturas rupestres donde se relacionan figuras de animales marinos y antropomorfos, como las de Quebrada Amarga en cercanías de la desembocadura del río Loa, El Médano y la franja litoral de Taltal (Artigas y García 2010; Gallardo et al. 2012). Todas ellas pinturas asociables al estilo El Médano, donde las embarcaciones son semilunares simples, casi siempre tripuladas por uno o dos navegantes cuyos cuerpos se construyen por una línea y están unidos a grandes y numerosas presas (cetáceos en su mayoría). Este estilo suele asociarse al período Intermedio Tardío (Mostny y Niemeyer 1983; Niemeyer 2010), no obstante pudo iniciarse con anterioridad considerando que las representaciones de peces y embarcaciones han sido encontradas en sitios arcaico tardíos de Taltal (p.ej., Núñez y Contreras 2009) (Figura 8B) ${ }^{6}$.

Finalmente, llama la atención que en la forma más temprana del icono -si aceptamos las asociaciones visuales- prima la representación de dos flotadores, mientras en las más tardías solo uno. Un indicador cronológico que habría que discutir con mayores antecedentes.

\section{Discusión}

La región de Tarapacá tiene una prehistoria particular que la distingue culturalmente de los Valles Occidentales y del Desierto de Atacama. Tempranos procesos de intensificación económica, creciente sedentarismo y nucleamiento poblacional en la franja de oasis afectaron a las poblaciones de la costa, quebradas altas y altiplano (p.ej., Meighan 1980; Núñez 1965, 1971, 1974, 1982; Núñez y Moraga 1983). Mediante caravanas de llamas o simples grupos pedestres, la circulación favoreció un tipo de complementariedad económica y social cuya integración no es comparable con aquellas descritas para las áreas vecinas (p.ej., Briones et al. 2005; Núñez 1962, 1976).

En este escenario formativo, las aldeas de Caserones y Guatacondo pudieron operar como ejes articuladores debido a su favorable emplazamiento geográfico y ecológico, en especial si se considera su asociación a los múltiples recursos forestales del bosque tarapaqueño, irracionalmente depredado por la minería desde la época colonial temprana 

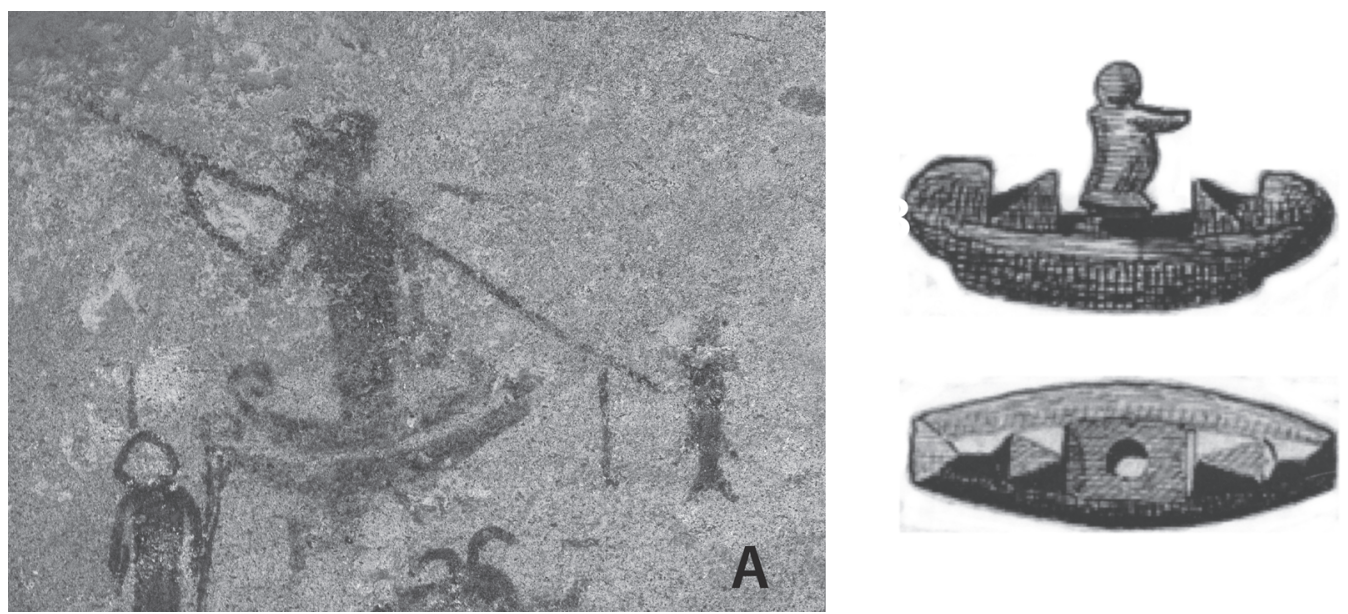

B

Figura 8. (A) Balsero estilo Confluencia (pintura roja). (B) Balsa tripulada en hueso, cementerio arcaico de Punta Morada (Taltal) (Núñez y Contreras 2009:106-107).

(A) Confluencia style Boatman (red painting). (B) Manned Boat on bone, from the Punta Morada archaic cemetery (Taltal) (Núñez and Contreras 2009:106-107).

(O’Brien en Hidalgo 2009:34-35). Por esto no resulta sorprendente comprobar que es en esta misma franja longitudinal donde se sitúan Tamentica y Ariquilda, dos sitios de arte rupestre que, como pocos, muestran una vigencia iconográfica que puede rastrearse desde el Formativo Temprano al período Intermedio Tardío.

La amplia distribución regional de los iconos claves descritos en este artículo, su permanencia en el tiempo y su presencia relativa en las localidades del Alto Loa y Loa Medio sugieren prácticas simbólicas y sociales referidas al consenso necesario para la coexistencia y movilidad de personas, bienes y conocimientos. Mientras en Tarapacá este marco cotradicional de interacción social contribuyó a la integración cultural de poblaciones de distintas ecozonas en el perfil costa-altiplano, es probable que la incorporación de localidades del río Loa dentro de este sistema visual haya sido resultado de una situación fronteriza que estuvo en funcionamiento hasta el período Colonial (Cases y Montt 2013; Gallardo et al. 2012; Martínez 1990; Pimentel y Montt 2008).

Tamentica cuenta con el mayor número de grabados en la quebrada de Guatacondo. Más aún, se emplaza en un inusual afloramiento rocoso asociado a un manantial de escurrimiento permanente. Sabemos también que en sus inmediaciones se registraron un importante cementerio del complejo Pica Tarapacá (950-1.450 d.C.) y una vasija cerámica con modelado antropomorfo similar a una del cementerio formativo de Topater, y que es un punto donde confluyen rutas prehispánicas que provienen tanto del norte como del sur (Mostny 1970a, 1970b; Tolosa 1967). Esta particular importancia es mayor si se considera que los rasgos naturales aludidos tienen propiedades sagradas para los aymaras de la región (p.ej., Martínez 1976; Mostny y Niemeyer 1963). Sin duda, el sitio debe ser considerado como un nudo significativo de la etnogeografía prehistórica de la quebrada, lugar de privilegio que tuvo sus inicios durante el Formativo Temprano. Una época fundacional que influiría de manera persistente en la integración cultural de la región hasta por lo menos el período Intermedio Tardío. Momento en que estos iconos claves seguirían vigentes, ampliando y diversificando sus soportes, así como seguramente también su significado y rol social.

\section{Conclusiones}

La quebrada de Guatacondo albergó procesos de sedentarismo formativo de escala sólo comparable a aquellos de la Quebrada de Tarapacá, con un patrón de vida aldeana con grandes recintos diseñados para la congregación social (Urbina et al. 2012). Su asociación espacial a grandes obras de irrigación y cultivo, bosques de algarrobo y emplazamientos mineros pudieron fomentar una economía excedentaria y un número relativamente importante de población, condiciones materiales que debieron haber servido de base para una prestigiosa 
función como nodo en la red de movilidad que regía los intercambios entre las diferentes comunidades de la costa, la Pampa del Tamarugal, el altiplano boliviano y el río Loa. Su importancia económica, simbólica y social -que perduró hasta el período colonial- queda de manifiesto también en los innumerables geoglifos que flanquean los accesos a la quebrada desde el cerro Challacoyito hasta el sector de Tiquima (Clarkson y Briones 2001; Mostny 1970a, 1970b). Pero de los registros rupestres al interior del valle, con poca duda el sitio de Tamentica resulta excepcional tanto por su emplazamiento, variedad y número de motivos. La iconografía allí presente $-\mathrm{y}$ sus asociaciones a artefactos de data conocida- sabemos que fue objeto de una revisita por largo tiempo y que ésta debió iniciarse hacia la época formativa.

Entre los iconos claves fundacionales del imaginario prehistórico tarapaqueño, el personaje con faldellín, armas arrojadizas y tocado dentado, el ave emplumada con atributos de Psittacidae y las balsas tripuladas parecen referenciar una trilogía de ecozonas diversas. Apelación ostentosa de una pertenencia simbólica y social que supera los límites de la localidad, instalándose como una representación de pertenencia gobernada por la complementariedad y lo intercultural. La construcción política de este conjunto visual y su función integradora adquirió gran importancia para las poblaciones de la región, pero su distribución espacial más allá de Tarapacá sugiere que este prestigio no fue contemplado con indiferencia por quienes eran sus vecinos en el desierto de Atacama.

Agradecimientos: a Mauricio Uribe y su equipo por materializar el registro de este y otros sitios de arte rupestre tarapaqueño, particularmente a Constanza Pellegrino y Rolando Ajata por su abnegada colaboración en la primera campaña de Tamentica (y a nuestro hijo Ignacio por su silenciosa pero prominente presencia en la segunda). También comprometen nuestra gratitud Sandra Vicentelo Albornoz y su madre, por permitirnos trabajar el sitio que se emplaza en su propiedad. Así como don Félix Aimani y doña Gloria Palape por su constante hospitalidad. Finalmente, agradecemos a Christina Torres-Rouff por sus correcciones al inglés y a los evaluadores anónimos que contribuyeron a mejorar este artículo. Esta investigación es resultado del proyecto FONDECYT 1080458.

\section{Referencias Citadas}

Artigas, D. y J. García 2010. Quebrada amarga: El encuentro de albacoras y llamas. Global Rock Art. Actas del Congreso Internacional de Arte Rupestre IFRAO Fundhamentos IX:1365-1380.

Aschero, C. 1988. Pinturas rupestres, actividades y recursos naturales; un encuadre arqueológico. En Arqueología Contemporánea Argentina: Actualidad y Perspectivas, editado por H. Yaccobaccio, L. Borrero, L. García, G. Politis, C. Aschero y C. Bellelli, pp. 109-145. Ediciones Búsqueda, Buenos Aires.

Augustyniak, S. 2004. Dating the Tiwanaku State. Chungara Revista de Antropología Chilena 36:19-35.

Ballester, B. y F. Gallardo 2011. Prehistoric and Historic networks on the Atacama desert coast (northern Chile). Antiquity 85(329):875-889.

Berenguer, J. 1981. En torno a los motivos biomorfos de la puerta del sol en el norte de Chile. Boletín del Museo Nacional de Historia Natural 38:167-182.

- - - 2004. Cinco milenios de arte rupestre en los andes atacameños: Imágenes para lo humano, imágenes para lo divino. Boletín del Museo Chileno de Arte Precolombino 9:75-108.

Blanco, J.F. 2012. La vía costa-Quillagua, sus sitios y ocupaciones extractivas. Proyecto Fondecyt 1090762, año 3. Manuscrito en posesión del autor.
Briones, L. y R. Ajata 2004. Puesta en valor y protección del yacimiento arqueológico de Tamentica-1. Informe Final. Manuscrito en posesión de los autores.

Briones, L. y C. Castellón 2005. Catastro de geoglifos. Provincia de Tocopilla, Región de Antofagasta. Consejo Nacional de la Cultura y las Artes FONDART, Tocopilla.

Briones, L., Núñez L. y V. Standen 2005. Geoglifos y tráfico prehispánico de caravanas de llamas en el desierto de Atacama (norte de Chile). Chungara Revista de Antropología Chilena 37:195-223.

Cabello, G., F. Gallardo y C. Odone 2013. Las pinturas costeras de Chomache y su contexto social (región de Tarapacá, norte de Chile). Boletín del Museo Chileno de Arte Precolombino 18(1), en prensa.

Cases, B. e I. Montt 2013. Las túnicas rupestres pintadas de la cuenca media y alta del Loa vistas desde Quillagua (norte de Chile). Chungara Revista de Antropología Chilena 45:249-275.

Catalán, D. 2006. Una Aproximación a las Expresiones Simbólicas e Ideológicas Tarapaqueñas a Partir del Ritual Funerario de Pica8 y la Costa de Iquique (Período Intermedio Tardío). Memoria para optar al título profesional de Arqueólogo, Departamento de Antropología, Universidad de Chile, Santiago. 
Clarkson, P. y L. Briones 2001. Geoglifos, senderos y etnoarqueología de caravanas en el desierto chileno. Boletín del Museo Chileno de Arte Precolombino 8:33-45.

Chacama, J. 2004. Hombres, pájaros y hombres-pájaros. Análisis de figuras humanas y aves sobre roca. Quebrada de Aroma, sitio Ariquilda 1, extremo norte de Chile. En Simbolismo y Ritual en Loa, Andes Septentrionales, editado por M. Guinea, pp. 167-187. Editorial Abya-Yala y Editorial Complutense, Quito-Madrid.

Chacama, J. y G. Espinosa 1997. La ruta de Tarapacá: análisis de un mito y una imagen en el norte de Chile. Actas del XIV Congreso Nacional de Arqueología Chilena, Tomo 1, pp.769792. Museo Regional de Atacama, Copiapó.

Donnan, C. 1978. Moche Art of Peru Communication. Museum of Cultural History, University of California, Los Angeles.

Focacci, G. y S. Erices 1972-1973. Excavaciones en túmulos de San Miguel de Azapa (Arica, Chile). Boletín de Prehistoria Número Especial:47-62.

Gallardo, F. 1996. Acerca de la lógica en la interpretación del arte rupestre. Boletín de la Sociedad Chilena de Arqueología 23:31-33.

- - - 2009a. Social interaction and early rock art styles in the Atacama Desert (Northern Chile). Antiquity 83:619-633.

- - - 2009b. Sobre la composición y la disposición en el arte rupestre de Chile: Consideraciones metodológicas. Magallania 37:19-38.

Gallardo, F., G. Cabello, G. Pimentel, M. Sepúlveda y L. Cornejo 2012. Flujos de información visual, interacción social y pinturas rupestres en el desierto de Atacama (norte de Chile). Estudios Atacameños 43:35-52.

Gallardo, F., C. Sinclaire y C. Silva 1999. Arte rupestre, emplazamiento y paisaje en la cordillera del desierto de Atacama. En Arte rupestre en los Andes de Capricornio, editado por J. Berenguer y F. Gallardo, pp. 57-96. Museo Chileno de Arte Precolombino, Santiago.

Gamble, C. 1982. Interaction and Alliance in Palaeolithic Society. Man 1:92-107.

Gombrich, E.H. 1969. Art and illusion. Bollingen Series XXXV 5, Princeton University Press, Princeton.

González, A.R. 1977. Arte Precolombino de la Argentina. Filmediciones Valero, Buenos Aires.

Hidalgo, J. 2009. Civilización y fomento: La "Descripción de Tarapacá" de Antonio O'Brien, 1765. Chungara Revista de Antropología Chilena 41:5-44.

Labarca, R. y F. Gallardo. 2012. The Domestic Camelids (Cetartiodactyla: Camelidae) from the Middle Formative Cemetery of Topater 1 (Atacama Desert, Northern Chile): Osteometric and Palaeopathological Evidence of Cargo Animals. (18 agosto). http://onlinelibrary.wiley.com/doi/10.1002/oa.2263/ abstract (1 octubre 2013).

Le Paige, G. 1977. Recientes descubrimientos arqueológicos en la zona de San Pedro de Atacama. Estudios Atacameños 5:109-124.

Lindeberg, I. 1969. Conchi Viejo. Una capilla y ocho casas. Actas del V Congreso Nacional de Arqueología, pp. 59-73. Museo Arqueológico de La Serena, La Serena.
Llagostera, A. 2004. Los Antiguos Habitantes del Salar de Atacama: Prehistoria Atacameña. Pehuén Editores, Santiago.

Llagostera, A. y M. A. Costa 1984. Museo Arqueológico R.P. Gustavo Le Paige S.J. Departamento de Extensión Cultural del Ministerio de Educación. Universidad del Norte, San Pedro de Atacama.

Martínez, G. 1976. El sistema de los Uywiris en Isluga. En Homenaje al Dr. Gustavo Le Paige, S.J., editado por H. Niemeyer, pp. 255- 327. Universidad del Norte, Antofagasta.

Martínez, J.L. 1990. Interetnicidad y complementariedad en el altiplano meridional: el caso atacameño. Andes 1:11-30.

- - - 1995. Autoridades en los Andes. Los Atributos del señor. Universidad Católica del Perú, Fondo Editorial, Lima.

Mege, P. 2003. Rewe y Clava, signos mapuches: estrategias de acción icónica de las organizaciones mapuches. Revista Chilena de Antropología Visual 3:17-32.

Meighan, C.W. 1980. Archaeology of Guatacondo. En Prehistoric trails of Atacama: Archaeology of Northern Chile, Monumenta Archaeologica 7, editado por C.W. Meighan y A.L. True, pp. 99-126. The Institute of Archaeology, University of California, Los Angeles.

Montt, I. 2002. Faldellines del Período Formativo en el Norte Grande: un ensayo acerca de la historia de su construcción visual. Estudios Atacameños 23:7-22.

- - - 2004. Elementos de atuendo e imagen rupestre en la subregión de río Salado, Norte Grande de Chile. Actas XV Congreso de Arqueología Chilena. Chungara Revista de Antropología Chilena Vol. 36 Número Especial, Tomo 2, pp. 651-661.

Mostny, G. 1970a. Arqueología de la Quebrada de Guatacondo. Órbita Revista de Ciencia y Tecnología 6:6-20.

- - - 1970b. La subárea arqueológica de Guatacondo. Boletín del Museo de Historia Natural XXIX:271-287.

Mostny, G. y H. Niemeyer 1963. II. Informe sobre investigaciones arqueológicas en la quebrada de Guatacondo. Museo Nacional de Historia Natural Noticiario Mensual 86:2-6.

- - - 1983. Arte Rupestre Chileno. Ministerio de Educación, Departamento de Extensión Cultural, Santiago.

Niemeyer, H. 1969. Los petroglifos de Taltape (Valle de Camarones, Provincia de Tarapacá). Boletín del Museo Nacional de Historia Natural XXX:95-117.

- - - 2010. Crónica de un Descubrimiento. Las Pinturas Rupestres de El Médano, Taltal. Museo Chileno de Arte Precolombino, Santiago.

Núñez, L. 1962. Contactos culturales prehispánicos entre la costa y la subcordillera andina. Boletín de la Universidad de Chile 31:43-47.

- - - 1965. Caserones, una aldea prehispánica del Norte de Chile. Estudios Arqueológicos 2:25-29.

- - - 1971. Secuencia y cambio en los asentamientos humanos de la desembocadura del río Loa en el Norte de Chile. Boletín de la Universidad de Chile 112:3-25.

- - - 1974. Agricultura prehistórica en los Andes Meridionales. Editorial Orbe, Universidad del Norte, Santiago. 
- - - 1976. Geoglifos y tráfico de caravanas en el desierto chileno. Homenaje al Dr. Gustavo Le Paige, S.J., editado por H. Niemeyer, pp. 147-201. Universidad del Norte, Antofagasta.

- - - 1982. Temprana emergencia de sedentarismo en el desierto chileno: proyecto Caserones. Chungara 9:80-122.

- - - 1985. Petroglifos y tráfico en el desierto chileno. En Estudios en Arte Rupestre, editado por C. Aldunate, J. Bereguer y V. Castro, pp. 243-264. Museo Chileno Arte Precolombino, Santiago.

Núñez, L. y C. Moragas 1983. Cerámica Temprana en Cáñamo (costa desértica del norte de Chile): análisis y evaluación regional. Chungara 11:31-61.

Núñez, L., I. Cartajena, C. Carrasco y P. de Souza 2006. El templete Tulán de la Puna de Atacama: Emergencia de complejidad ritual durante el Formativo Temprano (norte de Chile). Latin American Antiquity 17:445-473.

Núñez, L., I. Cartajena, C. Carrasco, P. de Souza y M. Grosjean 2006. Emergencia de comunidades pastoralistas formativas en el sureste de la Puna de Atacama. Estudios Atacameños 32:93-117.

Núñez, P. y R. Contreras 2009. A propósito de una miniatura de la balsa en Taltal, contemporánea con Chinchorro. Taltalia 2:98-110.

Pimentel, G. 2011. Geoglifos e imaginarios sociales en el desierto de Atacama. En Temporalidad, Interacción y Dinamismo Cultural. La Búsqueda del Hombre. Homenaje al Profesor Lautaro Núñez Atencio, editado por A. Hubert, J.A. González y M. Pereira, pp. 163-200. Ediciones Universitarias, Universidad Católica del Norte, Antofagasta.

Pimentel, G. e I. Montt 2008. Tarapacá en Atacama. Arte rupestre y relaciones intersocietales entre el 900 y 1450 d.C. Boletín del Museo Chileno de Arte Precolombino 13:35-50.

Rivera, M., D. Shea, A. Carevic y G. Graffam 1995-1996. En torno a los orígenes de las sociedades complejas andinas:
Excavaciones en Ramaditas, una aldea formativa del desierto de Atacama, Chile. Diálogo Andino 14-15:205-239.

Sepúlveda, M., A. Romero y L. Briones 2005. Tráfico de caravanas, arte rupestre y ritualidad en la quebrada de Suca (extremo norte de Chile). Chungara Revista de Antropología Chilena 37:225-243.

Sinclaire, C. 1997. Pinturas rupestres y textiles formativos en la región atacameña. Estudios Atacameños 14:327-338.

Thomas, C., M.A. Benavente, I. Cartajena y L. Contreras 2002. Una secuencia de fechados por termoluminiscencia para la localidad de Chiu-Chiu: sitios Chiu-Chiu 273 y 275. Boletín de la Sociedad Chilena de Arqueología 33/34:84-89.

Tolosa, B. 1963. Petroglifos de Tamentica. Museo Nacional de Historia Natural Noticiario Mensual 86:1.

- - - 1967. Descripción de los petroglifos de la zona arqueológica de Tamentica. Revista de la Universidad del Norte 3:3-12.

Urbina, S., L. Adán y C. Pellegrino 2012. La arquitectura formativa de Guatacondo y Tarapacá vista a través del proceso aldeano, norte de Chile. Boletín del Museo Chileno de Arte Precolombino 17:31-60.

Vilches, F. y G. Cabello 2010. Arte rupestre y asentamiento en el Complejo Pica-Tarapacá: las imágenes como indicadores de identidad y complejidad social. Actas del XVII Congreso de Arqueología Chilena, Tomo 2, pp. 671-680. Universidad Austral, Valdivia.

- - - 2011. Variaciones sobre un mismo tema: el arte rupestre asociado al complejo Pica-Tarapacá, norte de Chile. Chungara Revista de Antropología Chilena 43:37-52.

Wobst, M. 1977. Stylistic behavior and information exchange. En For the Director: Research Essays in Honor of James B. Griffin, editado por Ch.E. Cleland, pp. 317-42. Museum of Anthropology, University of Michigan, Ann Arbor.

\section{Notas}

1 Para otras propuestas iconotemporales del mismo sitio ver Rivera et al. (1995-1996), Meighan (1980) y Núñez (1985).

2 La selección fue resultado de una evaluación preliminar de todos los bloques, la que consideró la variabilidad de los procedimientos constructivos y visuales involucrados en la generación de los motivos y un registro fotográfico. Luego, cada uno de los motivos fue registrado en cuanto tamaño (alto y ancho), técnica empleada (piqueteado, raspado, mixta), tipo de intervención gráfica (lineal, cuando el motivo es expresado a través de una línea de contorno; o areal, cuando el área modificada es equivalente al diseño), ancho del surco y presencia de superposiciones (un motivo realizado sobre otro, total o parcialmente) y composiciones (dos o más motivos que se configuran a partir de estructuras escénicas o simétricas, sensu Gallardo 2009b).

3 Vale la pena señalar que las superposiciones son muy escasas en el sitio, registrándose en sólo dos bloques $\left(\mathrm{N}^{\circ} 32\right.$ y 40) y compromete a 9 de los 445 motivos registrados, dos de los cuales corresponden a este estudio (Aves con Alas Extendidas) y son discutidos más adelante.
4 Preferimos usar la letra W para graficar la postura de ambos brazos en relación con el cuerpo del individuo, debido a que la comúnmente usada $\mathrm{V}$ se presta a confusión en tanto es aplicable tanto a la forma señalada como a los brazos simplemente alzados.

5 El sitio de Topater tiene dos fechas radiocarbónicas calibradas: 410-360 a.C. y 360-270 a.C. (Labarca y Gallardo 2012). Por otra parte, existe un fragmento de poste tallado con una representación acorde que fue recuperado por nuestro equipo en la superficie de uno de los recintos de la aldea de Ramaditas. Y si bien fue fechado por radiocarbón en 390-340 cal. a.C. $(p=0,95)$ y 320-200 cal. a.C. $(p=$ 0,95 ) (calibrados a 2 sigmas con el programa INTCAL09, Beta-314509), lo consideramos con precaución hasta que se realicen los debidos estudios tecnológicos.

6 La representación de un pez, hecha en hueso, proveniente del sitio arcaico Muelle de Piedra figura en el álbum fotográfico Industria de los pueblos prehistóricos de Chile de la Société Scientifique du Chili, atribuido a Augusto Capdeville probablemente durante los años veinte (Archivo en biblioteca del Museo Chileno de Arte Precolombino). 